Marquette University

e-Publications@Marquette

School of Dentistry Faculty Research and

Publications

Dentistry, School of

4-1-2017

\title{
Correlation between Subjective Nasal Patency and Intranasal Airflow Distribution
}

Kevin P. Casey

Medical College of Wisconsin

Azadeh A.T, Borojeni

Medical College of Wisconsin

Lisa J. Koenig

Marquette University, lisa.koenig@marquette.edu

John S. Rhee

Medical College of Wisconsin

Guilherme J.M. Garcia

Medical College of Wisconsin

Accepted version. Otolaryngology, Head and Neck Surgery, Vol. 156, No. 4 (April 1, 2017): 741-750.

DOI. (C) 2017 SAGE Publications. Used with permission. 
Marquette University

\section{e-Publications@Marquette}

\section{Dentistry Faculty Research and Publications/School of Dentistry}

This paper is NOT THE PUBLISHED VERSION; but the author's final, peer-reviewed manuscript. The published version may be accessed by following the link in the citation below.

Otolaryngology-Head and Neck Surgery, Vol. 156, No. 4 (2017): 741-750. DOI. This article is @ SAGE Publications and permission has been granted for this version to appear in e-Publications@Marquette. SAGE Publications does not grant permission for this article to be further copied/distributed or hosted elsewhere without the express permission from SAGE Publications.

\section{Correlation between Subjective Nasal Patency and Intranasal Airflow Distribution}

Kevin P. Casey

Medical College of Wisconsin

Azadeh A. T. Borojeni

Medical College of Wisconsin

Lisa J. Koenig

Marquette University

John s. Rhee

Medical College of Wisconsin

Guilherme J. M. Garcia

Medcical College of Wisconsin 


\begin{abstract}
Objectives

(1) Analyze the relationship between intranasal airflow distribution and subjective nasal patency in healthy and nasal airway obstruction (NAO) cohorts using computational fluid dynamics (CFD). (2) Determine whether intranasal airflow distribution is an important objective measure of airflow sensation that should be considered in future NAO virtual surgery planning.
\end{abstract}

\title{
Study Design
}

Cross-sectional.

\section{Setting}

Academic tertiary medical center and academic dental clinic.

\section{Subjects and Methods}

Three-dimensional models of nasal anatomy were created based on computed tomography scans of 15 patients with NAO and 15 healthy subjects and used to run CFD simulations of nasal airflow and mucosal cooling. Subjective nasal patency was quantified with a visual analog scale (VAS) and the Nasal Obstruction Symptom Evaluation (NOSE). Regional distribution of nasal airflow (inferior, middle, and superior) was quantified in coronal cross sections in the narrowest nasal cavity. The Pearson correlation coefficient was used to quantify the correlation between subjective scores and regional airflows.

\section{Results}

Healthy subjects had significantly higher middle airflow than patients with NAO. Subjective nasal patency had no correlation with inferior and superior airflows but a high correlation with middle airflow $(|r|=0.64$ and $|r|=0.76$ for VAS and NOSE, respectively). Anterior septal deviations tended to shift airflow inferiorly, reducing middle airflow and reducing mucosal cooling in some patients with NAO.

\section{Conclusion}

Reduced middle airflow correlates with the sensation of nasal obstruction, possibly due to a reduction in mucosal cooling in this region. Further research is needed to elucidate the role of intranasal airflow distribution in the sensation of nasal airflow.

\section{Keywords}

sensation of nasal airflow, nasal airway obstruction surgery, subjective nasal patency, computational fluid dynamics (CFD) simulations, virtual surgery planning 
Nasal airway obstruction (NAO) is one of the most common indications for otolaryngology referral ${ }^{1}$ and carries an estimated economic burden upward of $\$ 5$ billion annually. ${ }^{2}$ Many studies have aimed to improve diagnosis of this condition, with the goal of optimizing therapeutic outcomes. Despite these efforts, NAO remains a diagnostic challenge due to inconsistencies between subjective symptoms and clinical exam, ${ }^{3}$ as well as the lack of reliable symptomatic correlation with objective assessment of nasal function by methods such as rhinomanometry, peak nasal inspiratory flow (PNIF), and acoustic rhinometry. ${ }^{4-10}$

Given that current objective methods do little to identify specific, clinically significant anatomical sites of obstruction, the diagnosis of NAO, the decision to proceed with surgery, and the selection of structures to target are often based on surgeon intuition. The development of better objective methods to guide decision making may help improve the success rate of NAO surgery, which has been deemed unsatisfactory by many otolaryngologists. ${ }^{11,12}$ Short-term studies report surgical failure rates as high as $20 \%$ to $37 \%,{ }^{13-17}$ while long-term studies report even higher failure over time. ${ }^{7,11,18}$ For example, in a long-term study of septoplasty outcomes, the proportion of patients stating "my symptoms are gone" was $53 \%$ six months postoperatively but only $18 \%$ three to six years postoperatively. ${ }^{11}$ In today's setting of increasing focus on health care cost and utilization, accurate (and early) identification of patients with NAO with a high likelihood of surgical benefit is more important than ever. ${ }^{19,20}$

Recent literature using 3-dimensional nasal airway modeling and computational fluid dynamics (CFD) has identified key objective variables of nasal airflow and mucosal cooling that reliably correlate with subjective nasal patency ${ }^{21-23}$ and offer the potential for clinical application in virtual surgery planning. This body of literature proposes that while common tests such as rhinomanometry, PNIF, and acoustic rhinometry accurately measure nasal airflow resistance, perhaps mucosal cooling has the greatest clinical relevance to subjective patency. ${ }^{24,25}$

Zhao and Jiang ${ }^{26}$ recently reported that subjective nasal patency scores had a higher correlation with airflow near the middle turbinate than with peak heat flux in 22 healthy subjects. Therefore, the purpose of this study is to apply CFD to quantify the intranasal airflow distribution in a cohort of healthy and NAO subjects aimed at (1) investigating whether intranasal airflow distribution is abnormal in patients with NAO and (2) analyzing whether subjective nasal patency correlates with intranasal airflow distribution. Most important, if such a correlation exists, this knowledge may have potential for application in future virtual surgery planning for NAO corrective surgery.

\section{Methods}

\section{Patient Selection}

The research was performed under approval by the institutional review board at the Medical College of Wisconsin. Informed consent was obtained from each patient. This project is part of a larger study aimed at correlation of subjective and objective measures of nasal patency and their application to NAO virtual surgery. ${ }^{21,22,27-30}$

Twenty-seven patients with NAO undergoing corrective surgery (septoplasty, turbinectomy, and/or septorhinoplasty) were recruited between 2009 and 2013. Preoperative axial computed tomography (CT) scans were obtained in 0.6- $\mathrm{mm}$ increments with in-plane resolution of $0.31 \mathrm{~mm}$. Included patients were at least 16 years old and diagnosed with anatomic NAO (deviated septum, medically resistant turbinate hypertrophy, or nasal valve dysfunction) (see Table S1, in the online version of the article). 
Patients with nasal obstructive symptoms primarily due to rhinitis, sinusitis, or neoplastic or autoimmune processes (ie, not due to anatomic obstruction) were excluded.

Fifty-two healthy subjects undergoing cone-beam CT (CBCT) scans at Marquette University School of Dentistry for indications unrelated to nasal etiology were recruited. CBCT scans were obtained in 0.5$\mathrm{mm}$ increments with in-plane resolution of $0.5 \mathrm{~mm}$. Subjects were at least 18 years old, denied symptoms of nasal obstruction, and were nonsmokers for at least 3 months preceding their scan. Exclusion criteria were pregnancy, history of nasal surgery, severe nasal trauma, autoimmune disease, chronic sinusitis, severe allergies, or other sinonasal disease. Subjects were included if NOSE score $\leq 32$ based on the mean NOSE score (15) plus 1 standard deviation (17) of healthy individuals described in a recent literature review. ${ }^{28}$

The first 15 patients from each cohort were selected for evaluation, regardless of subjects' nasal cycle status. ${ }^{29}$ Within the NAO cohort (10 male, 5 female), 13 identified as white, 1 as Hispanic, and 1 as "other" ethnicity. Within the healthy cohort (4 male, 11 female), 8 identified as white, 3 as Hispanic, 3 as Asian, 1 as African American, and 1 as "other" ethnicity.

\section{Creation of 3-Dimensional Models}

Three-dimensional digital models of nasal passages (excluding paranasal sinuses) were created in Mimics 16.0 (Materialise, Plymouth, Michigan). Models were exported in STL format and imported into ICEM-CFD 14.0 (ANSYS, Canonsburg, Pennsylvania), where planar nostrils and outlet surfaces were created and the geometry was meshed with approximately 4 million tetrahedral cells.
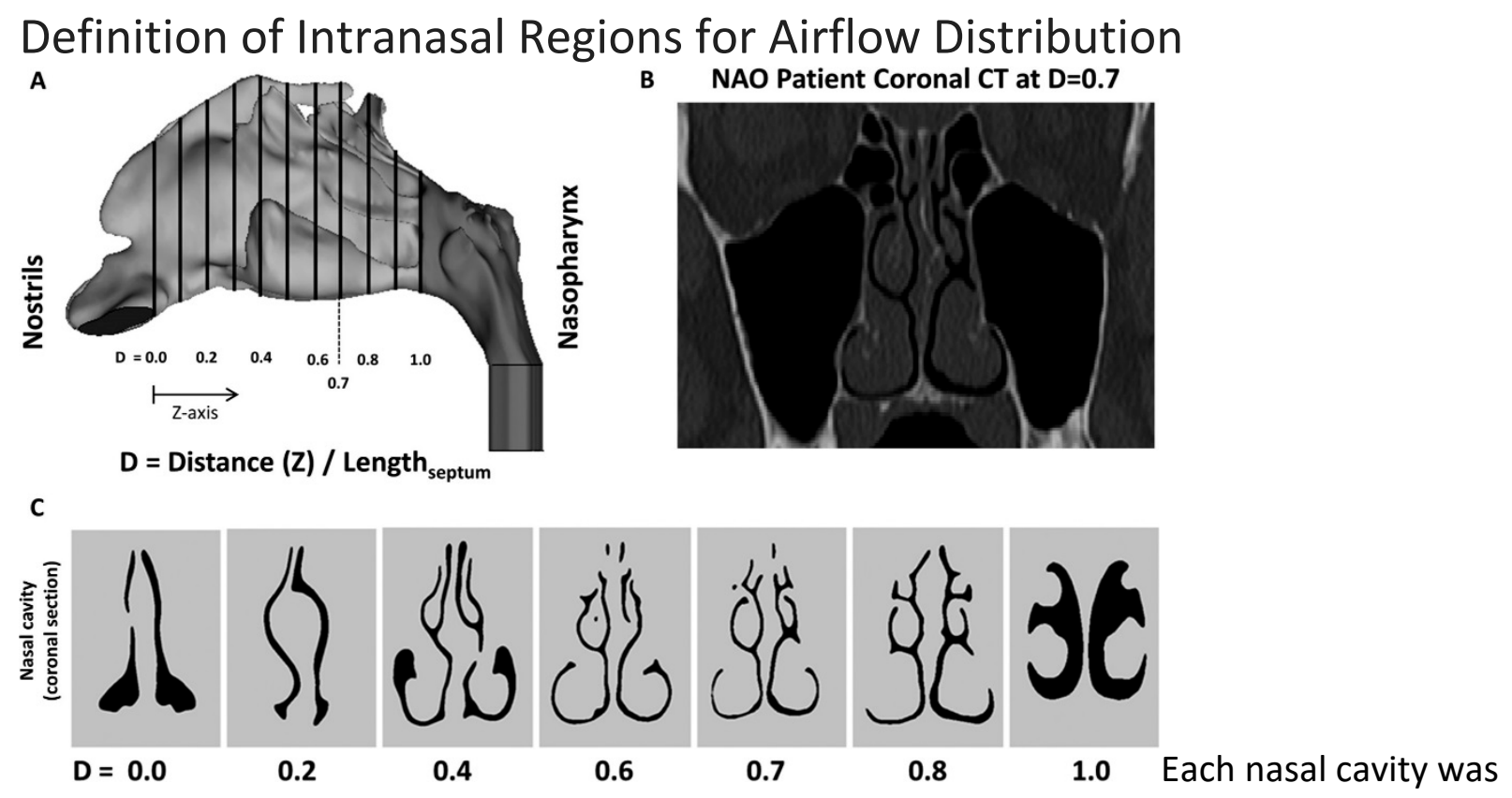

sectioned into 11 uniformly spaced coronal sections. The most posterior extent of either nostril was designated as relative distance $(D)=0.0$ and the posterior-most edge of the septum as $D=1.0$ (Figure 1). Coronal sections were labeled according to their relative distance from the nostril, as defined by $D=$ $Z / L_{\text {septum, }}$ where $Z$ is distance from the nostrils and $L_{\text {septum }}$ is septum length.

Figure 1. (A) Computational fluid dynamics of the nasal airway (sagittal view) demonstrating 11 equally spaced coronal cross sections. (B) Coronal computed tomography (CT) of patient with nasal airway obstruction (NAO) at $\mathrm{D}=0.7$. (C) Coronal cross sections of nasal cavity at corresponding relative distance (D). 


\section{REGIONAL AIRFLOW}

\section{Left Cavity \\ Right Cavity}

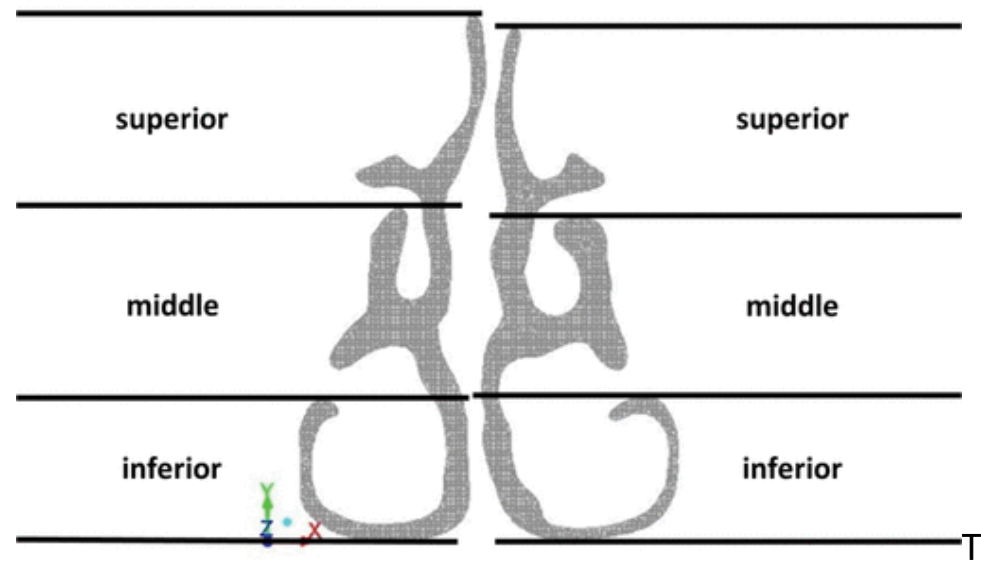

To analyze regional airflow, the coronal sections at $D=0.3, D=0.5$, and $D=0.7$ were divided into 3 vertical segments designated as inferior, middle, and superior regions independently for each nasal cavity using horizontal lines at the ventral lamella of each turbinate (Figure 2; see Figure S1 in the online version of the article). For clarity of presentation, the results for section $D=0.7$ are described below, while the results for sections $D=0.3$ and $D=0.5$ are presented in the online Appendix. Section $D=0.7$ was selected for presentation because it includes the inferior, middle, and superior turbinates in nearly all subjects. The main conclusions of this study were not dependent on the section selected for analysis (see Appendix, available online).

Figure 2. Each nasal cavity was vertically divided into inferior, middle, and superior regions at relative distance $\mathrm{D}=0.7$.

\section{CFD Simulations}

Our CFD modeling methods have been described in detail elsewhere. ${ }^{22,31}$ Steady-state inspiratory laminar airflow simulations were conducted in Fluent 14.0 (ANSYS) with the following boundary conditions: (1) air velocity set to zero at stationary walls, (2) pressure inlet at the nostrils with gauge pressure set to zero, and (3) an outlet pressure such that bilateral airflow was equal to $15 \mathrm{~L} / \mathrm{min}$. The outlet pressure required to obtain $15 \mathrm{~L} / \mathrm{min}$ of bilateral airflow was estimated by running preliminary simulations to quantify the relationship between outlet pressure and flowrate. Heat transfer simulation methods are described in detail in prior studies..$^{21,31}$

\section{Assessment of Subjective Nasal Patency}

All participants were administered the Nasal Obstruction Symptom Evaluation (NOSE) to assess disease-specific quality of life. This is a 5 -item scale in which patients rate symptoms of nasal congestion, nasal blockage, difficulty breathing through nose, difficulty sleeping, and air hunger sensation on a 0 (not a problem) to 4 (severe problem) scale. The score is then multiplied by 5 to give a score from 0 to 100 .

In addition, a unilateral visual analog scale (VAS) score was obtained. Patients were asked to cover one nostril and rate their ability to breathe on a 0 (no obstruction) to 10 (severe obstruction) scale. This was repeated for the contralateral nostril. The VAS score represented an assessment of subjective 
nasal patency at the time of administration, while the NOSE score reflected NAO symptoms during the preceding 30 days.

\section{Outcome Measures}

CFD simulations provided the following measurements of previously described objective measurements of nasal patency ${ }^{21,22}$ : (1) unilateral nasal airflow, (2) unilateral nasal resistance, (3) total unilateral heat flux, and (4) unilateral surface area where heat flux exceeds $50 \mathrm{~W} / \mathrm{m}^{2}$ (SAHF50). In addition, regional flow was quantified in inferior, middle, and superior regions (Figure 2).

\section{Statistical Analysis}

Wilcoxon signed-rank tests were used to test whether differences between the healthy and NAO cohorts were statistically significant at $P<.05$. The correlation coefficients between subjective and objective measures of nasal patency were computed using both the Pearson and Kendall's $\tau$ correlation coefficients, while trendlines were obtained using a least squares linear regression.

This article focuses on correlations between subjective nasal patency and unilateral measures of nasal airflow in the narrowest nasal cavity based on previous reports that (1) subjective nasal patency has a stronger correlation with unilateral rather than bilateral objective measures, ${ }^{5}$ and (2) subjective nasal patency has a stronger correlation with unilateral measures in the most obstructed side than with measures in the least obstructed side. ${ }^{22}$ The narrow side was defined as the cavity with lesser unilateral airflow in each individual. The correlation between subjective scores and intranasal airflow distribution in the nonnarrow side was also investigated, and the results are presented in the online Appendix.

\section{Results}

\section{Subjective Patency Scores}

Subjective nasal patency scores were significantly different between patients with NAO and healthy subjects measured by both NOSE ( $65 \pm 18$ vs $6 \pm 8$, respectively, $P<.0001)$ and VAS $(6.7 \pm 2.7$ vs $1.7 \pm$ 2.6 on the narrow side with $P<.001,3.3 \pm 2.3$ vs $1.4 \pm 2.5$ on the nonnarrow side with $P<.01$, respectively) (Figure 3 ). These data confirm a symptomatic distinction between cohorts as measured by NOSE and VAS scores. ${ }^{28}$
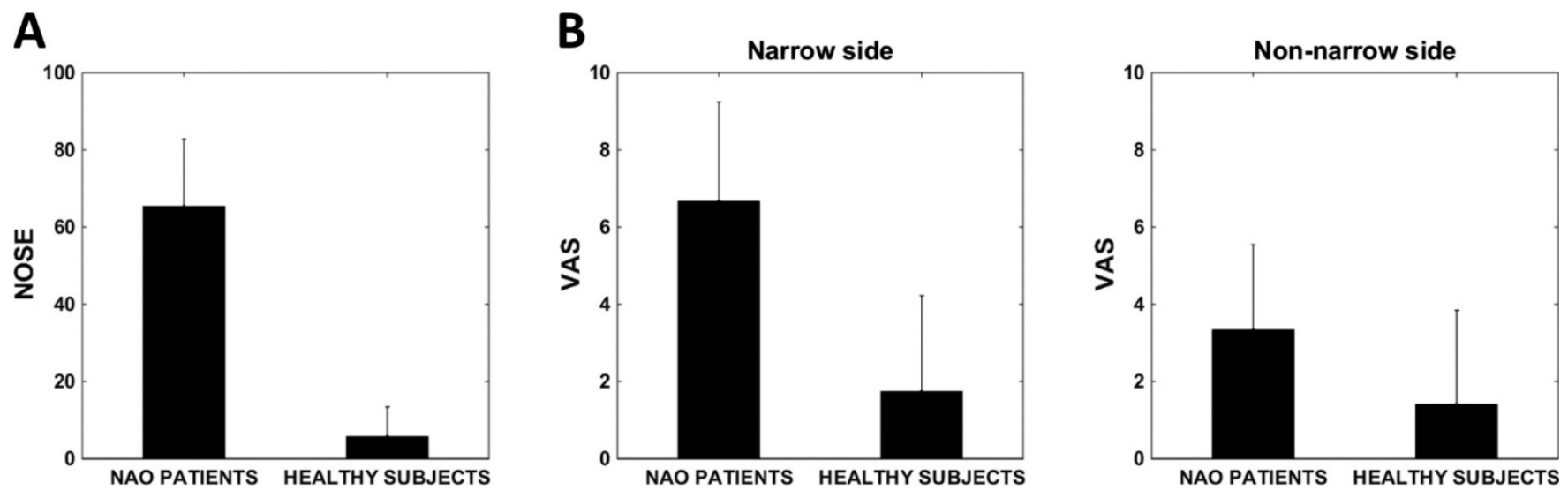

Figure 3. (A) Nasal Obstruction Symptom Evaluation (NOSE) scores in nasal airway obstruction (NAO) and healthy cohorts. (B) Visual analog scale (VAS) scores in NAO and healthy cohorts (narrow side). (C) VAS scores in NAO and healthy cohorts (nonnarrow side). Error bars: \pm 1 standard deviation. 


\section{Objective CFD Variables}

Unilateral CFD variables were analyzed separately for narrow and nonnarrow nasal cavities (Table 1). Unilateral nasal resistance was higher in patients with NAO than in healthy subjects in the narrow cavity (0.75 $\pm 1.4 \mathrm{~Pa} \cdot \mathrm{s} / \mathrm{mL}$ vs $0.10 \pm 0.04 \mathrm{~Pa} \cdot \mathrm{s} / \mathrm{mL}, P=.0006)$. Consequently, average unilateral airflow $(72 \pm 34 \mathrm{~mL} / \mathrm{s}$ vs $105 \pm 14 \mathrm{~mL} / \mathrm{s}, P=.0025)$, average unilateral heat flux (114 $\pm 54 \mathrm{~W} / \mathrm{m}^{2}$ vs $167 \pm 27$ $\left.\mathrm{W} / \mathrm{m}^{2}, P=.0055\right)$, and average unilateral SAHF50 (30 $\pm 13 \mathrm{~cm}^{2}$ vs $\left.41 \pm 5 \mathrm{~cm}^{2}, P=.007\right)$ were smaller in the narrow side of patients with NAO compared with healthy subjects.

Table I. Unilateral Computational Fluid Dynamics (CFD) Variables Previously Described as Correlating with Subjective Nasal Patency with Comparison of Mean Values between Patients with Nasal Airway Obstruction (NAO) and Healthy Subjects.

\begin{tabular}{|c|c|c|c|c|c|c|}
\hline \multirow[b]{2}{*}{ CFD Variables } & \multicolumn{3}{|c|}{ Narrow Side } & \multicolumn{3}{|c|}{ Nonnarrow Side } \\
\hline & NAO, Mean \pm SD & Healthy, Mean \pm SD & $P$ Value & NAO, Mean $\pm S D$ & Healthy, Mean \pm SD & $P$ Value \\
\hline Unilateral airflow, $\mathrm{mL} / \mathrm{s}$ & $72 \pm 34$ & $105 \pm 14$ & .0025 & $177 \pm 34$ & $145 \pm 14$ & .0025 \\
\hline Unilateral resistance, $\mathrm{Pa} \cdot \mathrm{s} / \mathrm{mL}$ & $0.75 \pm 1.45$ & $0.097 \pm 0.040$ & .0006 & $0.12 \pm 0.07$ & $0.07 \pm 0.03$ & .031 \\
\hline Unilateral heat flux, $\mathrm{W} / \mathrm{m}^{2}$ & $114 \pm 54$ & $167 \pm 27$ & .0055 & $230 \pm 35$ & $212 \pm 15$ & .12 \\
\hline $\begin{array}{l}\text { Surface area where heat } \\
\text { flux }>50 \mathrm{~W} / \mathrm{m}^{2}, \mathrm{~cm}^{2}\end{array}$ & $30 \pm 13$ & $4 I \pm 5$ & .007 & $58 \pm 8$ & $50 \pm 5$ & .0048 \\
\hline
\end{tabular}

The correlation between unilateral CFD variables and subjective patency scores was analyzed for the entire cohort of 30 individuals combined together. Before looking at regional airflows, the 2 variables with the strongest correlation with subjective scores were total unilateral airflow (NOSE: $r=-0.55, P=$ .0016; VAS: $r=-0.49, P=.0056$ ) and unilateral SAHF50 (NOSE: $r=-0.55, P=.0016$; VAS: $r=-0.51, P=$ .0038) (Table 2).

Table 2. Pearson and Kendall's $\tau$ Correlation Coefficients, $95 \%$ Cls, and P Values between CFD Variables and Subjective Nasal Patency (NOSE and VAS Scores), Narrow Side Only.

\begin{tabular}{|c|c|c|c|c|c|c|}
\hline \multirow[b]{2}{*}{ Subjective Scores vs Objective Variable (Narrow Side) } & \multicolumn{3}{|c|}{ Pearson Correlation } & \multicolumn{3}{|c|}{ Kendall's $\tau$ Correlation } \\
\hline & $r$ & $95 \% \mathrm{Cl}$ & $P$ Value & $\rho$ & $95 \% \mathrm{Cl}$ & $P$ Value \\
\hline \multicolumn{7}{|l|}{ NOSE } \\
\hline Unilateral airflow, $\mathrm{mL} / \mathrm{s}$ & -0.55 & -0.24 to -0.76 & .0016 & -0.35 & -0.14 to -0.56 & .001 \\
\hline Unilateral resistance, $\mathrm{Pa} \cdot \mathrm{s} / \mathrm{mL}$ & - & - & NS & 0.40 & 0.21 to 0.58 & $<.0001$ \\
\hline Unilateral heat flux, $\mathrm{W} / \mathrm{m}^{2}$ & -0.48 & -0.14 to -0.72 & .0075 & - & - & NS \\
\hline SAHF50, $\mathrm{cm}^{2}$ & -0.55 & -0.24 to -0.76 & .0016 & -0.38 & -0.14 to -0.62 & .0016 \\
\hline Inferior region airflow, $\mathrm{mL} / \mathrm{s}$ & - & - & NS & - & - & NS \\
\hline Middle region airflow, $\mathrm{mL} / \mathrm{s}$ & -0.76 & -0.56 to -0.88 & $<.0001$ & -0.54 & -0.38 to -0.69 & $<.0001$ \\
\hline Superior region airflow, $\mathrm{mL} / \mathrm{s}$ & - & - & NS & - & - & NS \\
\hline \multicolumn{7}{|l|}{ VAS } \\
\hline Unilateral airflow, $\mathrm{mL} / \mathrm{s}$ & -0.49 & -0.16 to -0.73 & .0056 & -0.32 & -0.12 to -0.53 & .0018 \\
\hline Unilateral resistance, $\mathrm{Pa} \cdot \mathrm{s} / \mathrm{mL}$ & - & - & NS & 0.41 & 0.22 to 0.61 & $<.0001$ \\
\hline Unilateral heat flux, $\mathrm{W} / \mathrm{m}^{2}$ & -0.43 & -0.09 to -0.69 & .0166 & - & - & NS \\
\hline SAHF50, $\mathrm{cm}^{2}$ & -0.51 & -0.19 to -0.74 & .0038 & -0.37 & -0.17 to -0.58 & .0004 \\
\hline Inferior region airflow, $\mathrm{mL} / \mathrm{s}$ & - & - & NS & - & - & NS \\
\hline Middle region airflow, $\mathrm{mL} / \mathrm{s}$ & -0.64 & -0.36 to -0.81 & .0002 & -0.38 & -0.19 to -0.58 & .0002 \\
\hline Superior region airflow, $\mathrm{mL} / \mathrm{s}$ & - & - & NS & - & - & NS \\
\hline
\end{tabular}

Abbreviations: CFD, computational fluid dynamics; Cl, confidence interval; NOSE, Nasal Obstruction Symptom Evaluation; NS, not significant; SAHF50, surface area where heat flux $>50 \mathrm{~W} / \mathrm{m}^{2}$; VAS, visual analog scale; - , correlation coefficients and confidence intervals are not listed because the correlation was not statistically significant. 


\section{Regional Airflow Distribution}

Regional airflow distribution is graphically depicted in Figure 4. In the narrow cavity, only the average middle airflow differed significantly between cohorts, with patients with NAO having less middle airflow than healthy individuals ( $31 \pm 18 \mathrm{~mL} / \mathrm{s}$ vs $68 \pm 10 \mathrm{~mL} / \mathrm{s}$, respectively; $P<.0001$ ) (Figure 4). Analysis of regional airflow as a percentage of total unilateral airflow revealed that the main flow pathway was the middle region in healthy individuals $(66 \% \pm 9 \%$ vs $23 \% \pm 7 \%$ in the middle and inferior regions, respectively; $P<.0001)$. In contrast, similar percentages of inhaled air flowed through the middle and inferior regions in the narrow side of patients with NAO (39\% $\pm 13 \%$ middle region, $50 \% \pm$ $18 \%$ inferior region; $P=.16)$. This difference in airflow allocation between the 2 cohorts is further illustrated by the fact that middle flow exceeded inferior flow in the narrow cavity of all 15 healthy subjects, but in 7 of 15 patients with NAO, inferior flow was greater than middle flow. Superior airflow in the narrow side did not differ significantly between cohorts with $11 \% \pm 5 \%$ and $11 \% \pm 10 \%$ of inspired air reaching the superior region in healthy and NAO cohorts, respectively $(P=.23)$.
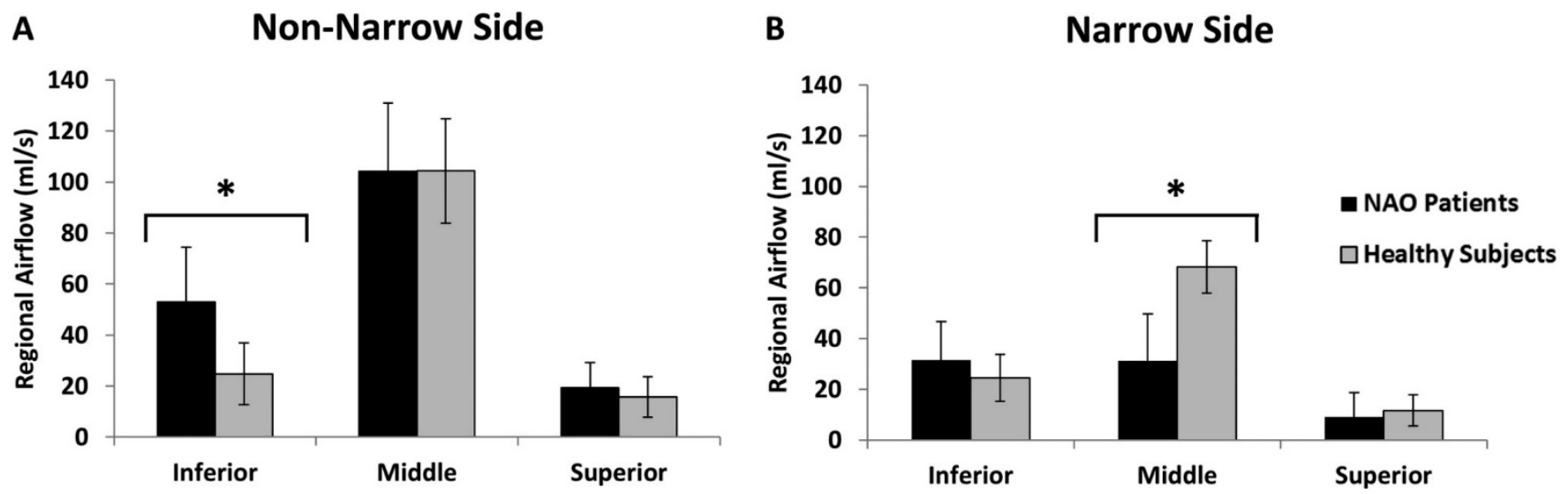

Figure 4. Regional airflow distribution in nasal airway obstruction (NAO) and healthy cohorts, (A) nonnarrow and (B) narrow sides. Asterisk $\left({ }^{*}\right)$ denotes statistically significant differences. Error bars: \pm 1 standard deviation.

\section{Subjective Patency vs Regional Airflow}

Subjective patency scores were plotted against narrow-side regional airflow (Figure 5). Narrow-side middle airflow demonstrated a strong correlation with both NOSE $(r=-0.76, P<.0001)$ and VAS scores $(r=-0.64, P=.0002)$, but inferior and superior airflows failed to correlate with subjective patency (Table 2 and Figure 5). The higher correlation of subjective patency with middle airflow is partially explained by a stronger correlation between total unilateral airflow and middle airflow $(r=0.90, P<$ $.0001)$ than between total unilateral airflow and inferior or superior airflows $(r=0.56, P=.001$ and $r=$ $0.49, P=.006$, respectively) (Figure 6). 


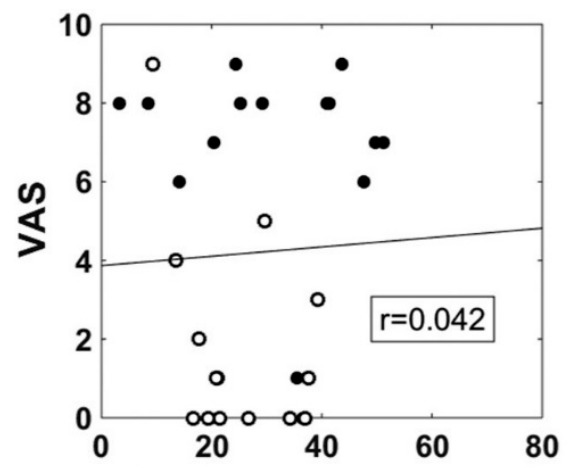

Airflow inferior region $(\mathrm{ml} / \mathrm{s})$

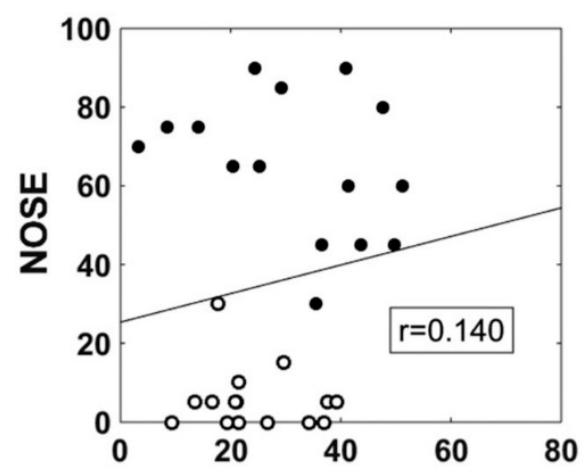

Airflow inferior region $(\mathrm{ml} / \mathrm{s})$

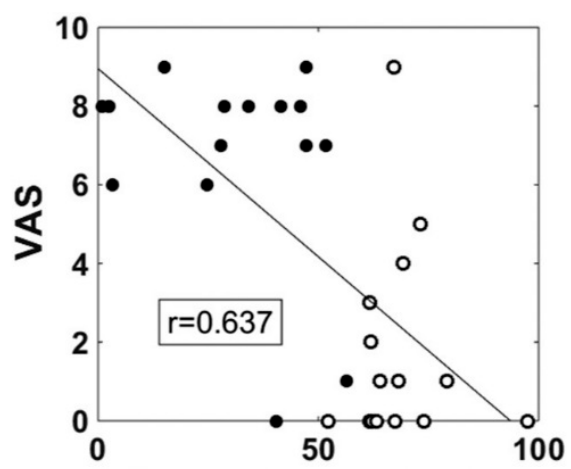

Airflow middle region $(\mathrm{ml} / \mathrm{s})$

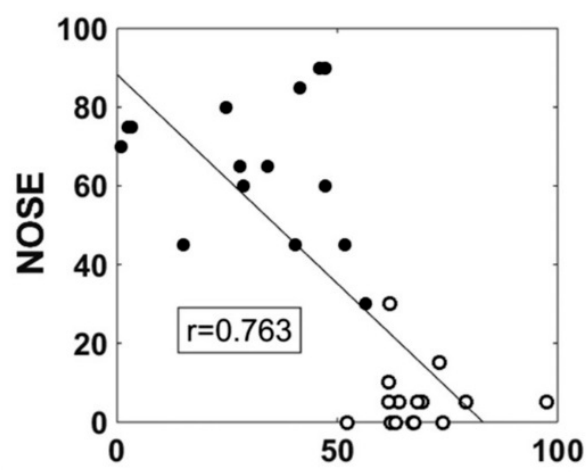

Airflow middle region $(\mathrm{ml} / \mathrm{s})$

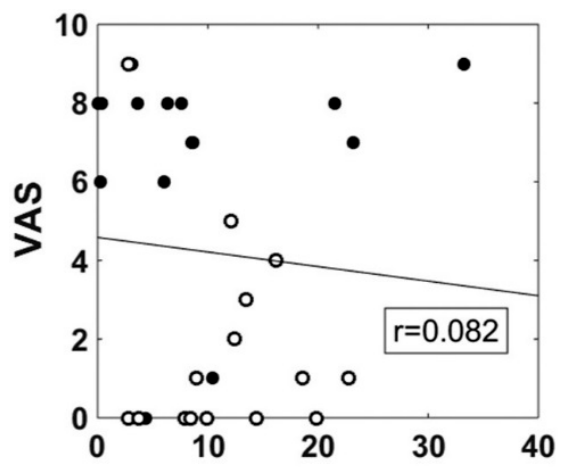

Airflow superior region $(\mathrm{ml} / \mathrm{s})$

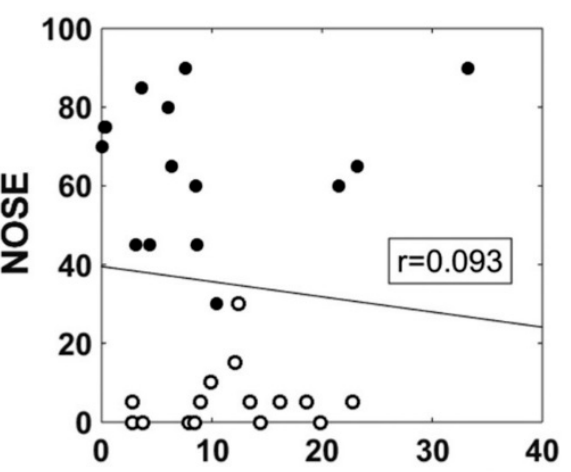

Airflow superior region $(\mathrm{ml} / \mathrm{s})$
- NAO PATIENTS
○ HEALTHY

Figure 5. Unilateral visual analog scale (VAS, top) and Nasal Obstruction Symptom Evaluation (NOSE, bottom) scores plotted against regional airflow (inferior, middle, superior) in the narrow side.
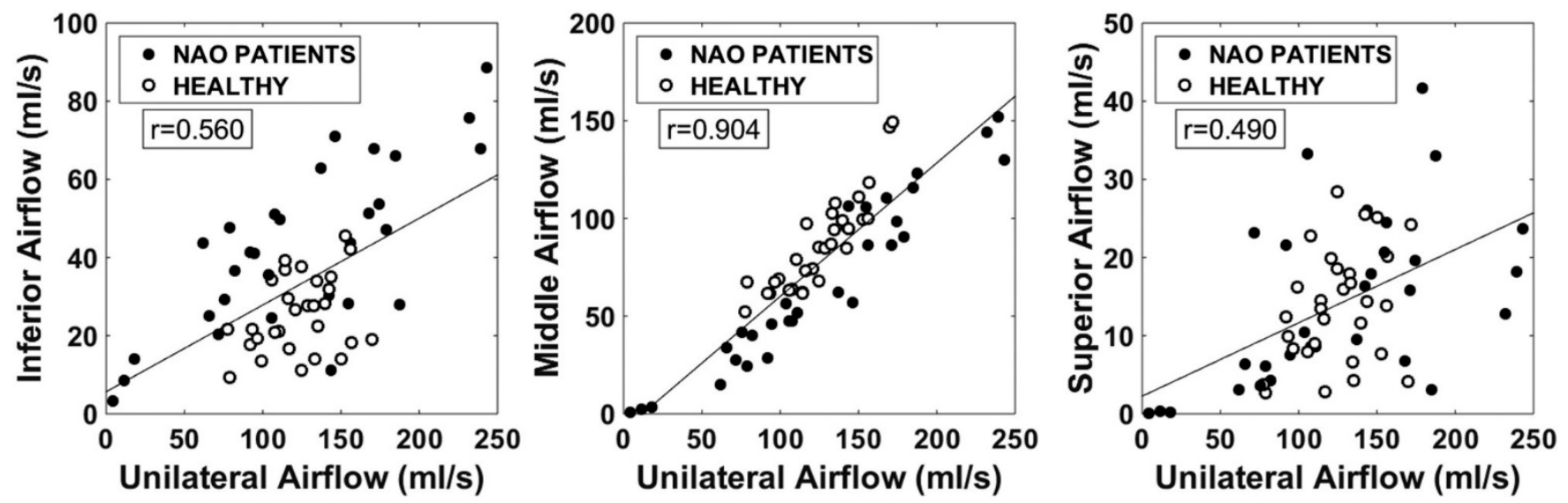

Figure 6. Unilateral regional airflow vs total unilateral airflow in nasal airway obstruction (NAO) and healthy cohorts. Both narrow and nonnarrow sides included (30 subjects, 60 nasal cavities).

\section{Effect of Anatomic Obstruction on Airflow Distribution}

We explored possible anatomical differences between patients with NAO and healthy individuals that may explain the different airflow distributions in the 2 cohorts. First, several patients with NAO (8 of 15) had anterior septal deviations constricting the nasal valve region (Figure 7A, B). These airway constrictions were usually located at the superior margin of the nasal valve, thus redirecting the airstream and favoring more inferior airflow in patients with NAO (Figure 7C). Second, there was a 
tendency for narrower nasal cavities to have less middle airflow $(r=-0.76, P<.0001)$ (Figure 8A). Finally, middle airflow also correlated with SAHF50 ( $r=0.46, P=.0002)$ (Figure 8B), suggesting that A HEALTHY SUBJECT
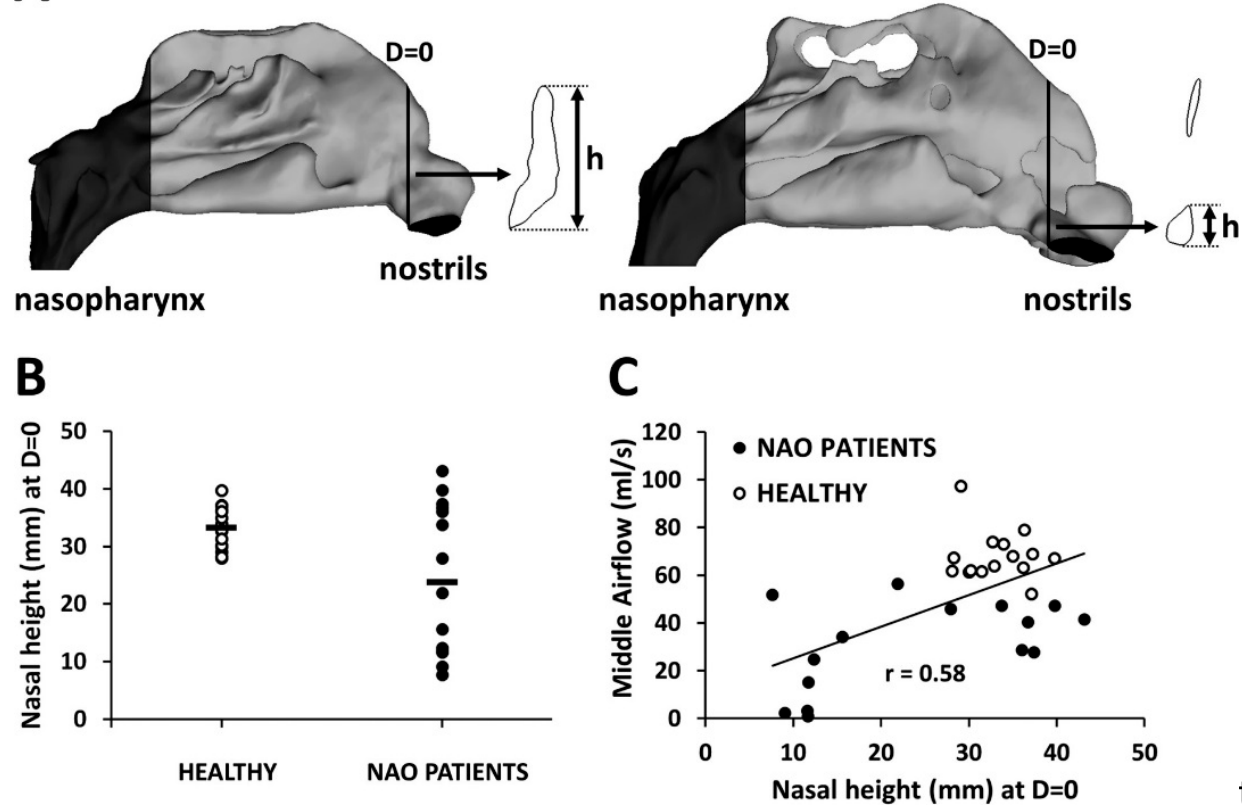

receptors in patients with low middle airflow.

there is less stimulation of cold

A

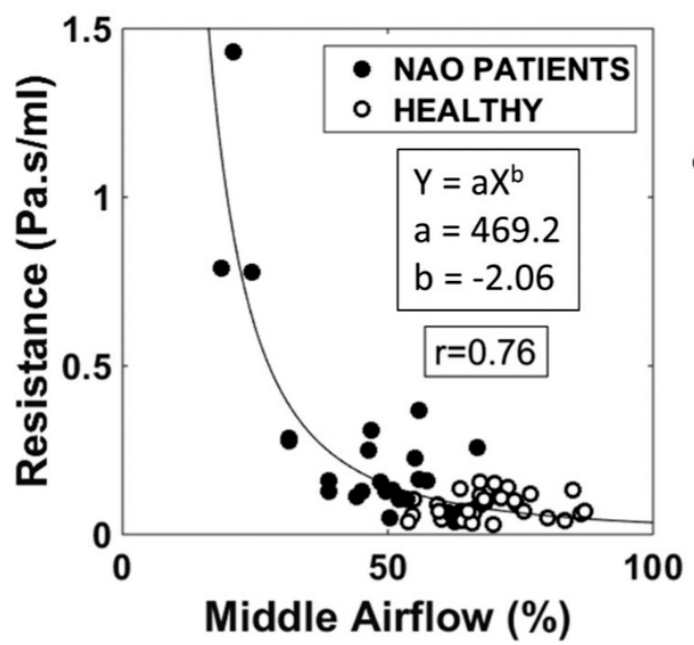

B

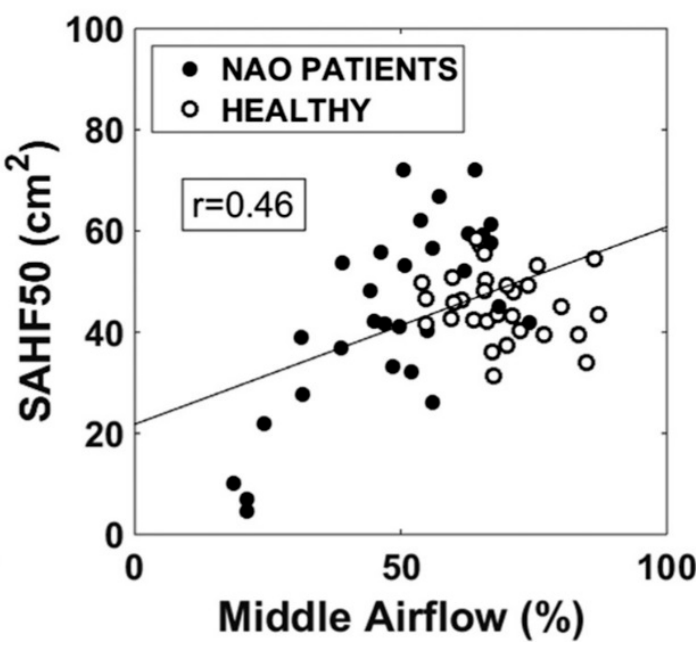
height (h) measured at $D=0$ in the narrow side. (C) Middle airflow was lower in patients with NAO with a small nasal height at $\mathrm{D}=0$.

Figure 8. The percentage of unilateral airflow passing through the middle region correlated with (A) the unilateral nasal resistance and (B) the surface area where heat flux exceeds $50 \mathrm{~W} / \mathrm{m}^{2}$ (SAHF50). NAO, nasal airway obstruction.

\section{Discussion}

The mechanism responsible for nasal airflow sensation remains incompletely understood. Multiple in vivo studies found that subjective nasal patency does not correlate with nasal resistance measured via rhinomanometry or the airspace minimal cross-sectional area (MCA) measured via acoustic rhinometry. ${ }^{4,5,8-10}$ This agrees with the concept that patients with NAO present due to a subjective 
perception of decreased patency rather than an objective reduction in nasal resistance. ${ }^{32}$ Certainly, resistance is a related entity, but it remains a distinctly different variable than subjective patency, ${ }^{9}$ which recent literature suggests may be more related to mucosal cooling. ${ }^{24}$

The effect of mucosal cooling on nasal patency has been studied for over a century. In 1927, Fox ${ }^{33}$ reported that volatile oils such as camphor, eucalyptus, and menthol improved patency perception without changing nasal resistance, which was supported by subsequent research in the 1980s and 1990s. ${ }^{34-36}$ Further support to the mucosal cooling hypothesis comes from the observation that subjects report improved nasal patency when inspiring dry air (as compared with room air at the same temperature) due to evaporative mucosal cooling. ${ }^{6}$

Earlier studies suggested that airflow sensation occurs primarily at the nasal vestibule. ${ }^{37,38}$ Jones and coauthors $^{32}$ reported that local anesthesia of the nasal vestibule produced a sensation of nasal obstruction. Clarke and Jones ${ }^{39}$ measured intranasal sensation to air jets and reported that the nasal vestibule is more sensitive to these mechanical stimulations than the posterior nose. Jones and colleagues ${ }^{40}$ measured the intranasal distribution of thermoreceptors using a cold probe and reported a higher density of thermoreceptors in the nasal vestibule relative to the nasal cavum. These studies suggested that the density of mechanoreceptors and thermoreceptors was not uniform within the nasal cavity, leading some investigators to conclude that the nasal mucosa has a limited role in airflow sensation and that the skin-lined nasal vestibule is the primary site for airflow sensation. ${ }^{37}$

Recent studies confirm that the mucosa of the nasal cavity is not a homogeneous tissue; rather, it consists of a heterogeneous distribution of sensory receptors. ${ }^{41,42}$ Frasnelli and colleagues ${ }^{42}$ used air puffs to determine that the mucosa of the anterior septum was more sensitive to $\mathrm{CO}_{2}$ while the posterior septum was more sensitive to mechanical stimuli. Meusel and collaborators ${ }^{41}$ measured trigeminal electrophysiological responses to several chemosensory stimuli, including menthol and $\mathrm{CO}_{2}$. While response to $\mathrm{CO}_{2}$ displayed an anterior-posterior gradient, menthol stimulation was similar throughout the nasal cavity, suggesting that menthol-sensitive cold receptors are uniformly distributed throughout the nasal cavity. Recent advances in molecular biomarkers have led to identification of a transient receptor potential cation channel, subfamily M, member 8 (TRPM8), as a cold- and mentholsensitive receptor, and inferior turbinate biopsies have confirmed its presence within nasal mucosa. ${ }^{43,44}$ Altogether, these studies demonstrate that trigeminal somatosensory neurons enable the detection of a wide range of environmental stimuli within the nasal mucosa, including pressure, temperature, and chemical irritants.

Recent CFD studies have confirmed that mucosal cooling correlates with subjective nasal patency. ${ }^{21,22,26}$ Kimbell and colleagues ${ }^{22}$ found a correlation $(|r|=0.65)$ between NOSE score and narrow-side unilateral heat flux. Zhao and Jiang ${ }^{26}$ also reported a correlation $(|r|=0.46)$ between peak heat flux posterior to the nasal vestibule and average VAS score. In a study by Sullivan and colleagues ${ }^{21}$ looking at pre- and postoperative patients with NAO, SAHF50 was determined to be the strongest predictor of nasal patency scores with a correlation of $|r|=0.76$ and $|r|=0.63$ for NOSE and VAS scores, respectively. These authors concluded that sensation of nasal patency was due to stimulation of cold receptors throughout the nasal mucosa (rather than at a single site where heat flux is maximum), which is consistent with the uniform distribution of TRPM8 receptors reported by Meusel and colleagues. ${ }^{41}$

Our study confirms the observation by Zhao and Jiang ${ }^{26}$ that subjective nasal patency correlates with intranasal airflow distribution (Figure 5; see Table S2, in the online version of the article). We expanded 
on their findings, demonstrating that (1) patients with NAO have a deficit in middle airflow in the narrow cavity compared with healthy individuals (Figure 4; see Figure S2, in the online version of the article), (2) subjective nasal patency has a stronger correlation with middle airflow in the narrow cavity than with any other regional airflow (Figure 5; see Figures S3-S7, in the online version of the article), (3) total unilateral airflow better correlates with middle airflow than inferior or superior airflows (Figure 6), (4) the abnormal airflow distribution in the NAO cohort is partially due to anterior septal deviations shunting airflow away from the middle region (Figure 7), and (5) intranasal airflow distribution correlates with both nasal resistance and SAHF50, suggesting that patients with a high nasal resistance tend to have less middle airflow and less stimulation of cold receptors (Figure 8).

Limitations of our study include the fact that we did not control for the nasal cycle. ${ }^{29}$ Both the NAO and healthy cohorts included some patients with asymmetric engorgement of the turbinates due to the nasal cycle. Our results (Figure 8) reveal that nasal cavities with high resistance tend to have less middle airflow, which suggests that intranasal airflow distribution may change during the nasal cycle. Future studies are needed to test this prediction. Another limitation of our study is that NAO symptoms can be caused by multiple anatomic deformities. We did not characterize airflow patterns by anatomic deformity (eg, deviated septum vs hypertrophied inferior turbinate). While future studies may consider characterizing airflow patterns by anatomic deformity, multiple anatomic deformities are often found concomitantly in the same patient (see Table S1, at www.otojournal.org/supplemental). Thus, we believe there is value in identifying CFD variables that correlate with subjective nasal patency in all-comers with NAO complaints. Finally, another limitation is that the 2 cohorts were not paired for demographics and an intercohort sex discrepancy was noted; however, prior studies have indicated that no significant sex difference exists in nasal resistance measurements. ${ }^{45-47}$

In summary, in a cohort of 15 healthy individuals and 15 patients with NAO, we found that patients with NAO had a deficit in airflow around the middle turbinate in the narrow cavity, which was strongly correlated with the perception of nasal obstruction. It is unclear whether this implies that mucosal cooling in the region surrounding the middle turbinate is especially important for the sensation of nasal airflow. To our knowledge, menthol-sensitive cold receptors have a uniform distribution on the nasal mucosa. ${ }^{41}$ However, the high correlation of middle airflow with subjective nasal patency raises an intriguing possibility that the 3-dimensional pattern of cold-receptor stimulation may be important for nasal airflow perception. Further research is required to confirm or refute this hypothesis.

\section{Acknowledgements}

We are grateful to Dr Purushottam Laud (Medical College of Wisconsin) for statistics support. We also thank Dr Julia Kimbell (UNC Chapel Hill) and Dr Dennis Frank-Ito (Duke University) for discussions on intranasal airflow distribution.

Sponsorships or competing interests that may be relevant to content are disclosed at the end of this article.

This article was presented at the 2016 AAO-HNSF Annual Meeting and OTO EXPO; September 18-21, 2016; San Diego, California.

\section{Supplemental Material}

Additional supporting information is available in the online version of the article. 


\section{References}

1. Teti, VP, Akdagli, S, Most, SP. Cost-effectiveness of corticosteroid nasal spray vs surgical therapy in patients with severe to extreme anatomical nasal obstruction. JAMA Facial Plast Surg. 2016;18(3):165170.

2. Kimmelman, CP. The problem of nasal obstruction. Otolaryngol Clin North Am. 1989;22:253-264.

3. Kjærgaard, T, Cvancarova, M, Steinsvåg, SK. Does nasal obstruction mean that the nose is obstructed? Laryngoscope. 2008;118:1476-1481.

4. Lam, DJ, James, KT, Weaver, EM. Comparison of anatomic, physiological, and subjective measures of the nasal airway. Am J Rhinol. 2006;20:463-470.

5. Andre, RF, Vuyk, HD, Ahmed, A. Correlation between subjective and objective evaluation of the nasal airway: a systematic review of the highest level of evidence. Clin Otolaryngol. 2009;34:518-525.

6. Zhao, K, Blacker, K, Luo, Y. Perceiving nasal patency through mucosal cooling rather than air temperature or nasal resistance. PLoS One. 2011;6:e24618.

7. Dinis, PB, Haider, H. Septoplasty: long-term evaluation of results. Am J Otolaryngol. 2002;23:85-90.

8. Hardcastle, PF, White, A, Prescott, RJ. Clinical and rhinometric assessment of the nasal airway-do they measure the same entity? Clin Otolaryngol Allied Sci. 1988;13:185-191.

9. Hardcastle, PF, White, A, Prescott, RJ. Clinical or rhinometric assessment of the nasal airway-which is better? Clin Otolaryngol Allied Sci. 1988;13:381-385.

10. Thulesius, HL, Cervin, A, Jessen, M. Can we always trust rhinomanometry? Rhinology. 2011;49:4652.

11. Sundh, C, Sunnergren, O. Long-term symptom relief after septoplasty. Eur Arch OtorhinoLaryngol. 2015;272:2871-2875.

12. Roblin, DG, Eccles, R. What, if any, is the value of septal surgery? Clin Otolaryngol Allied Sci. 2002;27:77-80.

13. Dommerby, H, Rasmussen, OR, Rosborg, J. Long-term results of septoplastic operations. ORL J Otorhinolaryngol Relat Spec. 1985;47:151-157.

14. Fjermedal, O, Saunte, C, Pedersen, S. Septoplasty and/or submucous resection? 5 years nasal septum operations. J Laryngol Otol. 1988;102:796-798.

15. Samad, I, Stevens, HE, Maloney, A. The efficacy of nasal septal surgery. J Otolaryngol. 1992;21:8891.

16. Illum, P. Septoplasty and compensatory inferior turbinate hypertrophy: long-term results after randomized turbinoplasty. Eur Arch Otorhinolaryngol. 1997;254(suppl 1):S89-S92.

17. Andre, RF, D'Souza, AR, Kunst, HP. Sub-alar batten grafts as treatment for nasal valve incompetence; description of technique and functional evaluation. Rhinology. 2006;44:118-122.

18. Konstantinidis, I, Triaridis, S, Triaridis, A. Long term results following nasal septal surgery: focus on patients' satisfaction. Auris Nasus Larynx. 2005;32:369-374. 
19. Sedaghat, AR, Busaba, NY, Cunningham, MJ. Clinical assessment is an accurate predictor of which patients will need septoplasty. Laryngoscope. 2013;123:48-52.

20. Holmstrom, M. The use of objective measures in selecting patients for septal surgery. Rhinology. 2010;48:387-393.

21. Sullivan, CD, Garcia, GJ, Frank-Ito, DO. Perception of better nasal patency correlates with increased mucosal cooling after surgery for nasal obstruction. Otolaryngol Head Neck Surg. 2014;150:139-147.

22. Kimbell, JS, Frank, DO, Laud, P. Changes in nasal airflow and heat transfer correlate with symptom improvement after surgery for nasal obstruction. J Biomech. 2013;46:2634-2643.

23. Zhao, K, Jiang, J, Blacker, K. Regional peak mucosal cooling predicts the perception of nasal patency. Laryngoscope. 2014;124:589-595.

24. Sozansky, J, Houser, SM. The physiological mechanism for sensing nasal airflow: a literature review. Int Forum Allergy Rhinol. 2014;4:834-838.

25. Bailey, RS, Casey, KP, Pawar, SS. Correlation of nasal mucosal temperature with subjective nasal patency in healthy individuals [published online ahead of print December 1, 2016]. JAMA Facial Plast Surg. doi:10.1001/jamafacial.2016.1445

26. Zhao, K, Jiang, J. What is normal nasal airflow? A computational study of 22 healthy adults. Int Forum Allergy Rhinol. 2014;4:435-446.

27. Kimbell, JS, Garcia, GJ, Frank, DO. Computed nasal resistance compared with patient-reported symptoms in surgically treated nasal airway passages: a preliminary report. Am J Rhinol Allergy. 2012;26:e94-e98.

28. Rhee, JS, Sullivan, CD, Frank, DO. A systematic review of patient-reported nasal obstruction scores: defining normative and symptomatic ranges in surgical patients. JAMA Facial Plast Surg. 2014;16:219225, quiz 232.

29. Patel, RG, Garcia, GJ, Frank-Ito, DO. Simulating the nasal cycle with computational fluid dynamics. Otolaryngol Head Neck Surg. 2015;152:353-360.

30. Garcia, GJ, Hariri, BM, Patel, RG. The relationship between nasal resistance to airflow and the airspace minimal cross-sectional area. J Biomech. 2016;49:1670-1678.

31. Garcia, GJ, Bailie, N, Martins, DA. Atrophic rhinitis: a CFD study of air conditioning in the nasal cavity. J Appl Physiol (1985). 2007;103:1082-1092.

32. Jones, AS, Crosher, R, Wight, RG. The effect of local anaesthesia of the nasal vestibule on nasal sensation of airflow and nasal resistance. Clin Otolaryngol Allied Sci. 1987;12:461-464.

33. Fox, N. Effect of camphor, eucalyptol and menthol on the vascular state of the mucous membrane. Arch Otolaryngol. 1927;6:112-122.

34. Burrow, A, Eccles, R, Jones, AS. The effects of camphor, eucalyptus and menthol vapour on nasal resistance to airflow and nasal sensation. Acta Otolaryngol. 1983;96:157-161.

35. Eccles, R, Lancashire, B, Tolley, NS. The effect of aromatics on inspiratory and expiratory nasal resistance to airflow. Clin Otolaryngol Allied Sci. 1987;12:11-14. 
36. Eccles, R, Griffiths, DH, Newton, CG. The effects of menthol isomers on nasal sensation of airflow. Clin Otolaryngol Allied Sci. 1988;13:25-29.

37. Clarke, RW, Jones, AS. Nasal airflow receptors: the relative importance of temperature and tactile stimulation. Clin Otolaryngol Allied Sci. 1992;17:388-392.

38. Clarke, RW, Jones, AS. Nasal airflow sensation. Clin Otolaryngol Allied Sci. 1995;20:97-99.

39. Clarke, RW, Jones, AS. The distribution of nasal airflow sensitivity in normal subjects. J Laryngol Otol. 1994;108:1045-1047.

40. Jones, AS, Wight, RG, Durham, LH. The distribution of thermoreceptors within the nasal cavity. Clin Otolaryngol Allied Sci. 1989;14:235-239.

41. Meusel, T, Negoias, S, Scheibe, M. Topographical differences in distribution and responsiveness of trigeminal sensitivity within the human nasal mucosa. Pain. 2010;151:516-521.

42. Frasnelli, J, Heilmann, S, Hummel, T. Responsiveness of human nasal mucosa to trigeminal stimuli depends on the site of stimulation. Neurosci Lett. 2004;362:65-69.

43. Keh, SM, Facer, P, Yehia, A. The menthol and cold sensation receptor TRPM8 in normal human nasal mucosa and rhinitis. Rhinology. 2011;49:453-457.

44. Liu, SC, Lu, HH, Cheng, LH. Identification of the cold receptor TRPM8 in the nasal mucosa. Am J Rhinol Allergy. 2015;29:e112-e116.

45. Broms, P. Rhinomanometry.. Procedures and criteria for distinction between skeletal stenosis and mucosal swelling. Acta Otolaryngol. 1982;94:361-370.

46. Vogt, K, Jalowayski, AA, Althaus, W. 4-Phase-rhinomanometry (4PR)-basics and practice 2010. Rhinol Suppl. 2010;(21):1-50.

47. Morris, S, Jawad, MS, Eccles, R. Relationships between vital capacity, height and nasal airway resistance in asymptomatic volunteers. Rhinology. 1992;30:259-264. 